\title{
Excessive Thyrotropin Response to Thyrotropin-releasing Hormone in Pseudohypoparathyroidism
}

\author{
EDMOND A. WERDER, ${ }^{(37)}$ RUTH ILLIG, SERGIO BERNASCONI, \\ HANSPETER KIND, AND ANDREA PRADER \\ Department of Pediatrics, University of Zürich, Zürich, Switzerland \\ JAN A. FISCHER \\ Research Laboratory for Calcium Metabolism, Department of Orthopedic Surgery and Department \\ of Medicine, University of Zürich, Zürich, Switzerland \\ ANDREAS FANCONI \\ Department of Pediatrics, Kantonsspital, Winterthur, Switzerland
}

\section{Extract}

In 8 of 10 patients with pseudohypoparathyroidism, confirmed by increased immunoreactive plasma parathyroid hormone concentrations and/or defective urinary excretion of adenosine $3^{\prime}, 5^{\prime}$-monophosphate (cAMP) after parathyroid extract infusion, excessive plasma thyrotropin (thyroid-stimulating hormone) (TSH) response to thyrotropin-releasing hormone (TRH) injection was found. On the other hand, in all seven cases with idiopathic true hypoparathyroidism the TSH response was normal. In two of three patients with pseudopseudohypoparathyroidism, with normal or slightly low plasma calcium, normal or slightly high immunoreactive plasma parathyroid hormone concentration, and intermediate response of cAMP to parathyroid extract, the TSH response to TRH was increased. The results indicate that moderate primary hypothyroidism is frequently present in pseudohypoparathyroidism. Thyroid dysfunction may only be detectable with the use of TSH stimulation by TRH, since clinical signs and other studies of thyroid function did not definitely suggest hypothyroidism in our patients. The rise of TSH is suppressible by thyroxine treatment, but is not influenced by vitamin D treatment. The TSH response to TRH is significantly correlated with the decrease of tubular reabsorption of phosphate after parathyroid extract infusion in patients with pseudo- and pseudopseudohypoparathyroidism.

\section{Speculation}

TSH stimulation by TRH may be a useful test for the further delineation of biochemical variants of pseudohypoparathyroidism.

The occasional association of hypothyroidism with pseudohypoparathyroidism had been suspected for several years (5, 22), but it was only proven in 1960 in a child described by Cohen and Donnell (5). Hypothyroidism was attributed to TSH deficiency, because the ${ }^{131}$ I uptake by the thyroid gland was increased markedly after TSH administration. Subsequent reports confirmed this finding in additional patients $(24,25$, 27). Recently, however, a mother and her 11-year-old daughter, who both suffered from pseudohypoparathyroidism, were found to have increased plasma immunoreactive $\mathrm{iSH}$ concentrations, which suggested a primary thyroid disorder rather than TSH deficiency (19). In the mother an excessive TSH response to TRH infusion was demonstrated. A similar observation in a child (17) prompted the present study of TSH stimulation by TRH in children and adults with pseudohypoparathyroidism. For comparison, TRH tests were also performed in patients with pseudopseudohypoparathyroidism and idiopathic true hypoparathyroidism.

\section{PATIENTS (TABLE 1)}

\section{PSEUDOHYPOPARATHYROIDISM}

Among the 10 patients tested were two groups of siblings $(K W, K R, K V$, and $E R, E N)$ and one pair of half-brothers $(S A$, $P M)$. Studies on patients $K W, K R, K V$, and $L S$ had been reported previously (7). Characteristic symptoms were psychomotor and intellectual retardation (seven cases), brachymetacarpia, brachymetatarsia, or shortened digits (six cases), obesity (five cases), short stature (four cases), ectopic calcifications (five cases), and radiologic signs of hyperparathyroidism (five cases). The diagnosis of pseudohypoparathyroidism was confirmed by high normal or increased concentrations of immunoreactive plasma parathyroid hormone (PTH) in 9 of 10 patients and by defective excretion of cAMP in urine after parathyroid extract (PTE) infusion (4) in all six patients tested. All of the patients were hypocalcemic and hyperphosphatemic before treatment, except for the three youngest patients ( $E R, S A, E N)$, who did not require vitamin D therapy. Their condition was classified as latent pseudohypoparathyroidism (12), since they showed the defective urinary cAMP response to PTE. Phosphaturic response to intravenous PTE was impaired in all except case ER. The calcemic response to serial intramuscular PTE given to four patients ( $P M, M P$, $K W$, and $M F$ ) during an earlier period without vitamin D treatment was low. In two patients with latent pseudohypoparathyroidism $(S A, E N)$, there was a clear-cut hypercalcemic response. Serum magnesium and protein concentrations and alkaline phosphatase activity were normal in all cases. 
Table 1. Data on patients with pseudo-, pseudopseudo-, and idiopathic hypoparathyroidism ${ }^{1}$

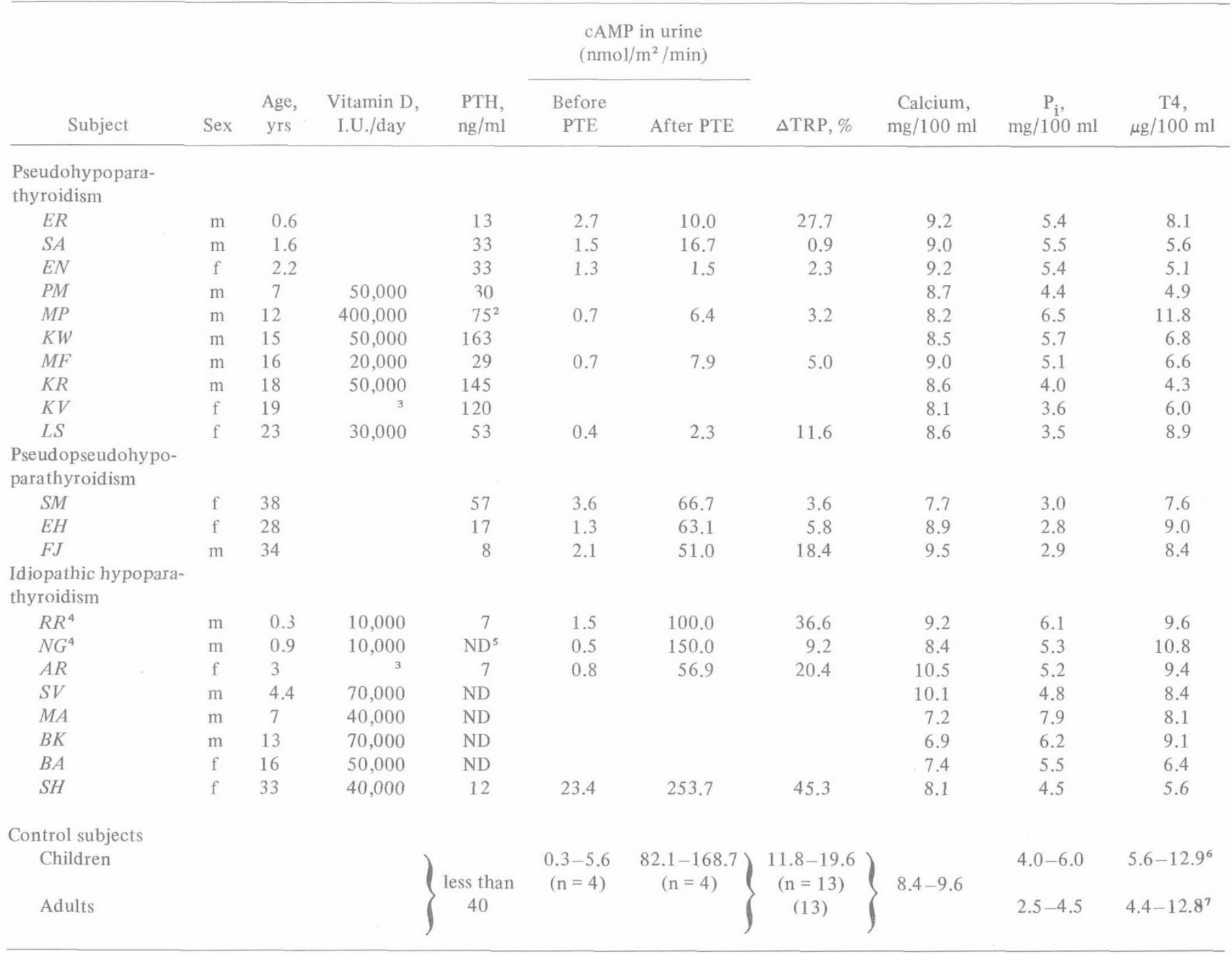

${ }^{1}$ PTH: parathyroid hormone; PTE: parathyroid extract; cAMP: adenosine $3^{\prime}, 5^{\prime}$-monophosphate; $\Delta$ TRP: decrease in tubular reabsorption of phosphate; $m$ : male; f: female.

${ }^{2}$ Before treatment.

${ }^{3}$ Treatment interrupted.

${ }^{4}$ Transient hypothyroidism.

${ }^{5} \mathrm{ND}$ : not detectable.

${ }^{6}$ Prepubertal range.

${ }^{7}$ Range after onset of puberty

\section{IDIOPATHIC HYPOPARATHYROIDISM}

Eight patients, including one pair of siblings $(B K, B A)$, were tested. The diagnosis was based on documented hypocalcemia and hyperphosphatemia in all cases and on undetectable (five case $(S M)$ with moderate hypocalcemia, plasma PTH was slightly elevated.

\section{CONTROL SUBJECTS}

TSH response to TRH was analyzed in 28 euthyroid children. In four patients aged 5.8-17.8 years with minor

\section{PSEUDOPSEUDOHYPOPARATHY ROIDISM}

These three probands were adult relatives (two mothers, one maternal uncle) of patients with pseudohypoparathyroidism whose clinical findings (brachymetacarpia, ectopic calcifications) suggested the same disorder. Because of their definite, although intermediate, cAMP response to PTE, they were classified as pseudopseudohypoparathyroid cases (4). In one case $(S M)$ with moderate hypocalcemia, plasma PTH slightly elevated. brachymetacarpia, cAMP response to PTE infusion was studied. The results of the decrease in tubular reabsorption of phosphate $(\triangle T R P)$ after intravenous PTE were compared with those obtained from 13 control patients of a previous study (14). The other control values appearing on Table 1 represent the experience of our laboratories. (Informed consent was obtained on all subjects tested.)

\section{MATERIALS AND METHODS}

Synthetic TRH (28) was injected intravenously within seconds in a single dose of $200 \mu \mathrm{g} / \mathrm{m}^{2}$ body surface area. Blood samples were obtained through indwelling cannulas inserted into an arm vein at 0,20 , and $60 \mathrm{~min}(10)$. The heparinized blood was centrifuged at $4^{\circ}$ and the plasma was stored at $-16^{\circ}$ until analyzed.

Intravenous PTE tests using the same lot of Para-Thor-Mone (29) at a dose of 300 I.U./1.73 $\mathrm{m}^{2}$ body surface area in all patients were performed according to the method of Chase et al. (4), but shortened to 1 day with 2 hourly urinary collections before PTE followed by two half-hourly and one to four hourly urine collections after PTE infusion. Intramuscular 
PTE tests were performed using different lots of Para-ThorMone (29) at a dose of 500 I.U. $/ \mathrm{m}^{2}$ body surface area divided into three daily doses for at least 2 days in responders and 4 days in nonresponders. The calcemic response was compared with the results obtained previously in pseudohypoparathyroidism and hypoparathyroidism (13).

TSH was assayed radioimmunologically with a double antibody method $(21,30)$; The results are expressed in terms of the TSH standard $68 / 38$ (31). The sensitivity of the assay system is $0.1 \mu \mathrm{U}$ and the range of best precision is between 0.2 and $2 \mu \mathrm{U}$.

Immunoreactive plasma PTH concentration was estimated by a slightly modified method of Arnaud et al. (1) using a crude human tissue standard (C-72). Dilution curves of the tissue culture standard and hyperparathyroid sera, using GP-1M antiporcine PTH (32), were superimposable, which indicated immunologic similarity (8). The level of cAMP in urine was determined according to the method of Brown et al. (3). The urine samples were kept frozen at $-16^{\circ}$ and, assayed in dilutions of $1: 10,1: 50,1: 500$, and $1: 2,500$. The sensitivity of the assay system is $0.2 \mathrm{pmol}$ and the range of optimal precision is between 0.5 and 10 pmol.

Total serum calcium was determined by automatic ethylene glycol bis( $\beta$-aminoethyl ether)- $N, N^{\prime}$-tetraacetic acid titration using calcein as an indicator (33). With this method the normal range is relatively low $(8.4-9.6 \mathrm{mg} / 100 \mathrm{ml})$. Serum and urinary inorganic phosphate $\left(\mathrm{P}_{\mathrm{i}}\right)$ were determined by a colorimetric method (11). Magnesium was measured by atomic absorption flame spectrophotometry.

Total serum thyroxine was measured by a protein binding method (20). Bone age was determined by the method of Greulich and Pyle (9).

\section{RESULTS}

The basal TSH concentrations were elevated in seven cases of pseudohypoparathyroidism and an excessive TSH response to TRH was noted in all except two patients $(E R, L S)$ (Fig. 1). On the other hand, in idiopathic hypoparathyroidism, both basal and peak TSH concentrations after TRH were normal (Fig. 2). The three patients with pseudopseudohypoparathy-

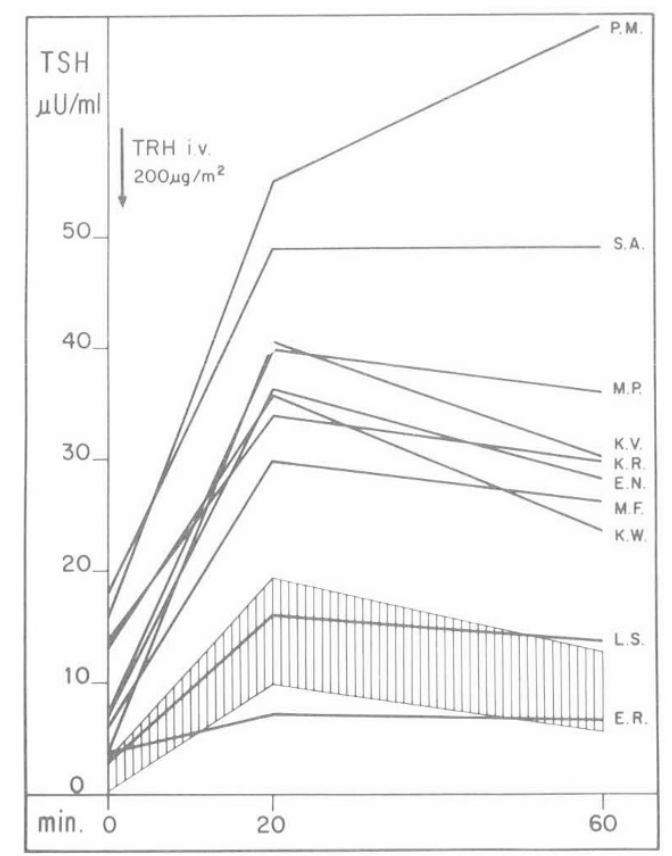

Fig. 1. Thyrotropin-releasing hormone $(T R H)$ test in pseudohypoparathyroidism $(\mathrm{n}=10)$. Normal thyrotropin $(T S H)$ response $($ mean \pm 1 $\mathrm{SD})$ is represented by the shaded area $(\mathrm{n}=28)$.

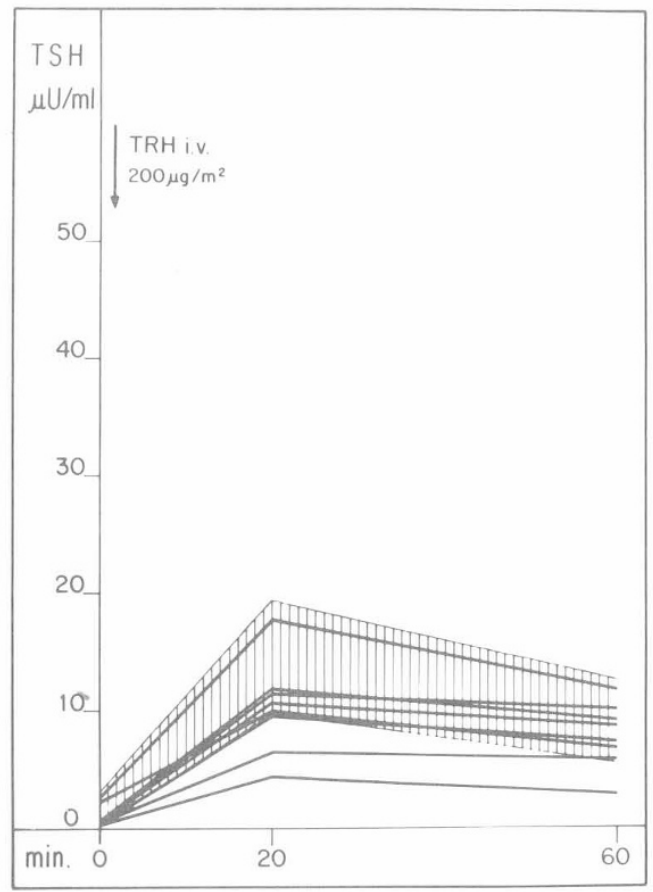

Fig. 2. Thyrotropin-releasing hormone $(T R H)$ test in idiopathic true hypoparathyroidism $(\mathrm{n}=8)$. TSH: thyrotropin.

roidism showed varying results of the TRH test (Fig. 3). They all had normal basal TSH levels. In two mothers $(S M, E H)$ the normal basal plasma TSH increased to elevated levels at $20 \mathrm{~min}$ after TRH injection and in one case $(S M)$ remained high at 60 $\min$.

The peak TSH levels in pseudo- and pseudopseudohypoparathyroidism showed a highly significant correlation with $\triangle T R P$ after PTE infusion (Fig. 4). There was no correlation of peak TSH with peak cAMP.

The patients with pseudohypoparathyroidism had no clinical signs of hypothyroidism and the size of their thyroid glands was normal. Plasma T4 concentrations were normal (seven cases) or slightly below the normal range (three cases) (Table 1). Thyroid antibodies (34) were not detectable. None of the patients had retarded bone age, in six cases it was even advanced by as much as 2.5 years. Thyroid function in pseudopseudohypoparathyroidism and in idiopathic hypoparathyroidism was normal. In three patients with pseudohypoparathyroidism the TRH test was repeated under treatment with $l$-thyroxine or triiodothyronine which showed blunting of the $\mathrm{TSH}$ response to TRH. In three patients tested during hypocalcemia (serum calcium: 5.6, $6.8,7.0 \mathrm{mg} / \mathrm{ml}$ ) the TSH response to TRH was not different from that obtained in normocalcemia during vitamin D treatment. The PTH level determined in five patients remained unchanged 20 and 60 min after TRH.

\section{DISCUSSION}

The results of the TRH test in the patients with pseudohypoparathyroidism suggest the presence of moderate primary hypothyroidism. The high plasma TSH concentrations rule out TSH deficiency. TSH released by TRH is considered to be the most sensitive index of thyroid function. Our cases illustrate that by measuring plasma TSH thyroid dysfunction can be detected despite normal serum thyroxine. From clinical observation it appears that most patients do not progress to overt thyroid failure, but occasional cases, as observed on follow-up in the patient reported by Malvaux and Beckers (17), may develop frank clinical hypothyroidism requiring treatment with thyroid hormones. This emphasizes the need for re-examination of thyroid function in patients with 


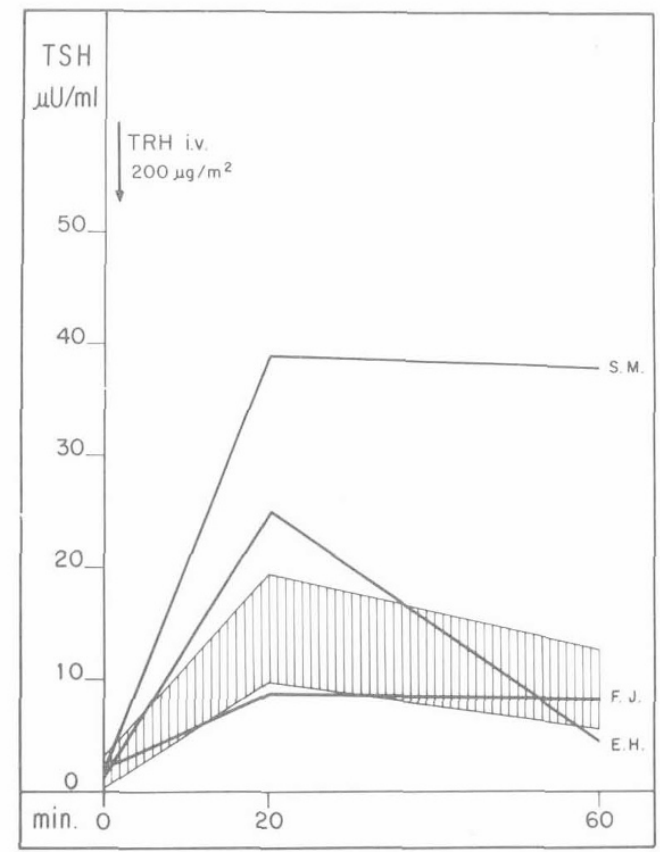

Fig. 3. Thyrotropin-releasing hormone $(T R H)$ test in pseudopseudohypoparathyroidism $(\mathrm{n}=3)$. TSH: thyrotropin.

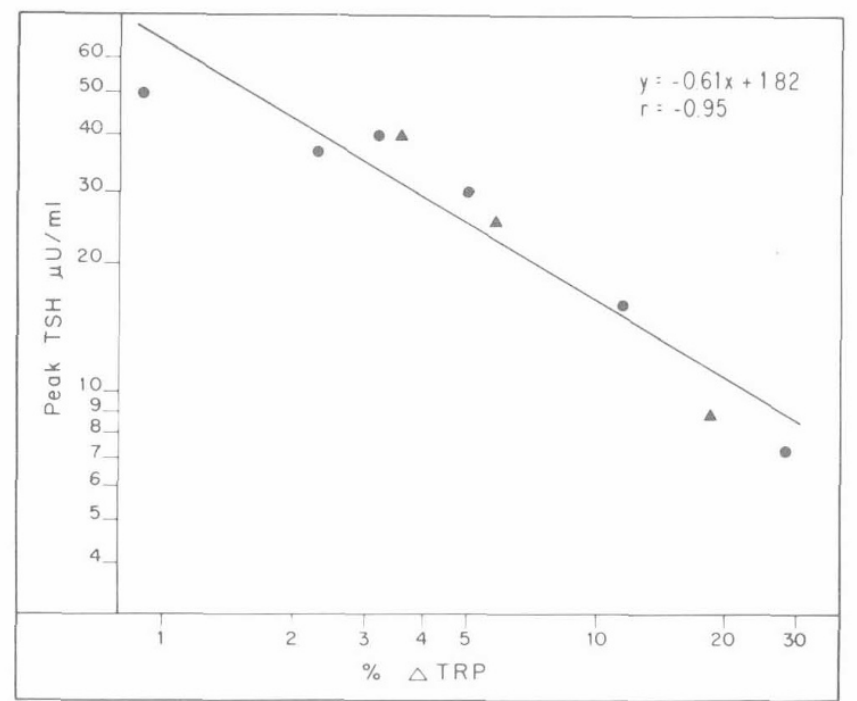

Fig. 4. Correlation of log peak thyrotropin (TSH) (microunits per milliliter) after thyrotropin-releasing hormone and log of decrease in tubular reabsorption of phosphate $(\triangle T R P)$ (percentage) after parathyroid extract infusion (data from Table 1) in pseudohypoparathyroidism $(\bullet)$ and pseudopseudohypoparathyroidism (A) (significance from $0, p<$ 0.001 .

pseudohypoparathyroidism and advocates hormonal treatment in all cases with excessive TSH release to prevent possible harmful effects of an unrecognized progressive thyroid disorder. In our youngest patient $(E R)$, who showed normal TSH stimulation although his older sister showed an increased level, the TRH test must be repeated since this infant may also develop demonstrable thyroid dysfunction.

Since the TSH response to TRH was almost consistently increased in pseudohypoparathyroidism in contrast to all the cases of idiopathic hypoparathyroidism, this test may be useful as an adjunctive diagnostic tool in the differentiation of these conditions. Although measurements of plasma PTH- and PTE-induced excretion of cAMP remain the diagnostic tests of prime importance, TSH responses to TRH stimulation may further delineate certain biochemical variants of pseudohypoparathyroidism. Although, in most cases, both cAMP and phosphate response to PTE are deficient, a few cases have been described with specific impairment of either cAMP (13) or phosphate $(6,14)$ excretion. Our case $S M$ illustrates the difficulties in classification of such patients. Although listed as a case of pseudopseudohypoparathyroidism because of the increase in cAMP excretion in urine after PTE, this patient could also be considered an example of pseudohypoparathyroidism on the hasis of clinical signs, elevated PTH, moderate hypocalcemia, and deficient phosphaturia. In accordance with the diminished phosphaturic response to PTE, excessive TSH stimulation by TRH was observed.

The results of the response of cAMP to PTE in pseudopseudohypoparathyroidism are of interest. They indicate that pseudopseudohypoparathyroidism may be characterized by an intermediate response, higher than in pseudohypoparathyroidism but lower than in normal subjects.

It has been speculated that the increase of plasma TSH and PTH may be secondary to a common intracellular defect in the mediation of the hormonal actions in both the thyroid gland and the renal tubule (19), in which these mechanisms are known to involve the activation of the cAMP-generating adenyl cyclase system (15). In target cells, cAMP, the second messenger of hormonal action (23), triggers the metabolic events necessary for the biologic effects. In pseudohypoparathyroidism PTH unresponsiveness of the renal cell is presumed to be due to a block of second messenger formation (2) or of message reception $(6,18)$. Specific hormonal receptors have been demonstrated for many hormones (16). At present there is only circumstantial evidence for specific PTH receptors in the renal cells (4) and TSH receptors in the thyroid tissue (26). A common defect of such presumably different and specific hormonal receptors in both organs seems to be an unlikely explanation for the elevated PTH and TSH observed in pseudohypoparathyroidism. It is conceivable, however, that the defect may be located in the chain of biochemical events elicited by cAMP. This view is compatible with the normal PTH sensitive adenyl cyclase activity found in the renal cortex of a patient (18).

\section{SUMMARY}

Plasma TSH response to intravenous TRH was studied in 10 patients with pseudohypoparathyroidism, 8 patients with idiopathic true hypoparathyroidism, and 3 patients with pseudopseudohypoparathyroidism. Excessive TSH responses were noted in 8 cases of pseudohypoparathyroidism, whereas all cases of idiopathic hypoparathyroidism showed a normal rise of TSH. TSH stimulation by TRH in pseudopseudohypoparathyroidism was variable. The results indicate that moderate hypothyroidism is often present in pseudohypoparathyroidism. TSH response to TRH in pseudo- and pseudopseudohypoparathyroidism is significantly correlated with the phosphaturic response to PTE.

\section{REFERENCES AND NOTES}

1. Arnaud, C., Tsao, H. S., and Littledike, E. T.: Radioimmunoassay of human parathyroid hormone in serum. J. Clin. Invest., 50: 21 (1971).

2. Bell, N. H., Avery, S., Sinha, T., Clark, C. M., Allen, D. O., and Johnston, C.: Effects of dibutyryl cyclic adenosine $3^{\prime}, 5^{\prime}$-monophosphate and parathyroid extract on calcium and phosphorus metabolism in hypoparathyroidism and pseudohypoparathyroidism. J. Clin. Invest., 51: 816 (1972).

3. Brown, B. L., Albano, J. D. M., Ekins, R. F., Sgherzi, A. M., and Tampion, W.: A simple and sensitive saturation assay method for the measurement of adenosine $3^{\prime}, 5^{\prime}$-cyclic monophosphate. Biochem. J., 121: 561 (1971).

4. Chase, L. R., Melson, G. L., and Aurbach, C. D.: Pseudohypoparathyroidism: Defective excretion of $3^{\prime}, 5^{\prime}$-AMP in response to parathyroid hormone. J. Clin. Invest., 48: 1832 (1969).

5. Cohen, M. L., and Donnell, G. N.: Pseudohypoparathyroidism with hypothyroidism. J. Pediat., 56: 369 (1960).

6. Drezner, M., Neelon, F. A., and Lebovitz, H. E.: Pseudohypoparathyroidism type II: Possible defect in reception of cyclic AMP signal. New Engl. J. Med., 289: 1056 (1973). 
7. Fanconi, A., Heinrich, H. G., and Prader, A.: Klinischer und biochemischer Hypoparathyroidismus mit radiologischem Hyperparathyreoidismus. Helv. Paediat. Acta, 19: 181 (1964).

8. Fischer, J. A., Binswanger, U., Rittel, W., and Dietrich, F. M.: Human parathyroid hormone: Immunological characterization of antibodies against the synthetic amino-terminal fragment 1-34 and their use in the determination of immunoreactive parathy roid hormone in human sera. In: S. Taylor: Endocrinology 1973 (W. Heinemann, London, 1974).

9. Greulich, W. W., and Pyle, S. I.: Radiographic Atlas of Skeletal Development of the Hand and Wrist, Ed. 2 (Stanford University Press, Stanford, 1959)

10. Hall, R., Amos, J., Garry, R., and Buxton, R. L.: Thyroid-stimulating hormone response to synthetic thyrotropin releasing hormone in man. Brit. Med. J., 2: 274 (1970).

11. Itaya, K., and Uli, M.: A new method for the colorimetric determination of inorganic phosphate. Clin. Chim. Acta, 14: 361 (1966).

12. Kind, H. P., Kooh, S. W., Parkinson, D. K., and Fraser, D.: Latent pseudohypoparathyroidism (Abstract). Pediat. Res., 8: 128 (1974).

13. Kind, H. P., Parkinson, D. K., Suh, S. M., Fraser, D., and Kooh, S. W.: Parathyroid hormone response and effects of vitamine D in hypoparathyroidism and pseudohypoparathyroidism (Abstract). Endocrinology (suppl.), 92: 164 (1973).

14. Kind, H. P., Parkinson, D. K., Suh, S. M., and Kooh, S. W.: A classification of the hypoparathyroid syndrome based on the PTH response test (Abstract). Pediat. Res., 7: 324 (1973).

15. Klainer, L. M., Chi, Y. M., Friedberg, S. L., Rall, J. W., and Sutherland, E. W.: Adenylcyclase. IV. The effects of neurohormones on the formation of adenosine $3^{\prime}, 5^{\prime}$-phosphate by preparations from brain and other tissues. J. Biol. Chem., 237: 1239 (1962).

16. Lefkowitz, R. J.: Isolated hormone receptors: Physiologic and clinical implications. New Engl. J. Med., 288: 1061 (1973).

17. Malvaux, P., and Beckers, C.: Serum thyrotrophin response to thyrotrophin releasing hormone in normal children and in patients with short stature and various endocrine and genetic diseases. Clin. Endocrinol., 2: 219 (1973); Personal communication.

18. Marcus, R., Wilber, J. C, and Aurbach, G. D.: Parathyroid hormone-sensitive adenylcyclase from the renal cortex of a patient with pseudohypoparathyroidism. J. Clin. Endocrinol., 33: 537 (1971).

19. Marx, S. J., Hershman, J. M., and Aurbach, G. D.: Thyroid dysfunction in pseudohypoparathyroidism. J. Clin. Endocrinol., 33: 822 (1971).

20. Murphy, B. E. P., Pattee, C. J., and Gold, A.: Clinical evaluation of a new method for the determination of serum thyroxine. J. Clin. Endocrinol., 26: 247 (1966).

Copyright (c) 1975 International Pediatric Research Foundation, Inc.
21. Odell, W. D., Wilber, J. F., and Paul, W. E.: Radioimmunoassay of thyrotropin in human serum. J. Clin. Endocrinol., 25: 1179 (1965).

22. Peterman, M. G., and Garvey, J. L.: Pseudohypoparathyroidism. Pediatrics, 4: 790 (1949).

23. Sutherland, E. W., Robinson, G. A., and Butcher, R. W.: Some aspects of the biological role of adenosine $3^{\prime}, 5^{\prime}$-monophosphate (cyclic AMP). Circulation, 37: 279 (1968).

24. Turner, R. W., and Takamura, T.: Pseudohypoparathyroidism and hypothyroidism. Ann. Intern. Med., 56: 276 (1962).

25. Winnacker, J. L., Becker, K. L., and Moore, C. F.: Pseudohypoparathyroidism and selective deficiency of thyrotropin; an interesting association. Metabolism, 16: 644 (1967).

26. Yamashita, K., and Field, J. B.: Preparation of thyroid plasma membranes containing a $\mathrm{TSH}$ responsive adenylcyclase. Biochem. Biophys. Res. Commun., 40: 171 (1970).

27. Zisman, E., Lotz, M., Jenkins, M. E., and Bartter, F. C.: Studies in pseudohypoparathyroidism. Two new cases with a probably selective deficiency of thyrotropin. Amer. J. Med., 46: 464 (1969).

28. Synthetic TRH was supplied by Hoffmann-La Roche Co., Basel, Switzerland.

29. Lilly, Indianapolis, Ind

30. Purified human TSH and anti-TSH were supplied by the National Pituitary Agency, Baltimore, Md.

31. The TSH standard was obtained from the National Institute for Medical Research, Division of Biological Standards, London.

32. The GP-1M antisera and the human tissue culture standard (C-72) were provided by Dr. C. D. Arnaud, Mayo Clinic, Rochester, Minn.

33. Marius calcium titrator, Utrecht, The Netherlands. Total serum calcium was assayed by Dr. U. Binswanger, Department of Medicine, Kantonsspital, University of Zürich, Switzerland.

34. Thyroid antibodies were determined by Dr. P. Grob, Department of Medicine, Kantonsspital, University of Zürich, Switzerland.

35. We gratefully acknowledge the help of Dr. P. Malvaux (Department of Pediatrics, University Hospital, Louvain, Belgium) who stimulated this investigation, and of Dr. P. Sigg (Department of Pediatrics, Schweizerische Pflegerinnenschule, Zürich, Switzerland) and Dr. Gertrud Mürset (Department of Pediatrics, University of Zürich, Switzerland) who allowed us to study their patients.

36. Drs. E. A. Werder, R. Illig, and J. A. Fischer were recipients of Grants nos. KFl, 3.678.71, and 3.807 .72 from the "Schweizerischer Nationalfonds zur Förderung der wissenschaftlichen Forschung."

37. Requests for reprints should be addressed to: E. A. Werder, M.D., Department of Pediatrics, University of Zürich, Kinderspital, Steinwiesstr. 75, 8032 Zürich, Switzerland.

38. Accepted for publication June 13, 1974. 